deployed by other writers to justify the existence of the poor.

In his peroration Epstein argues from (mostly unstated) first principles that substantially (but unspecifically) increased welfare expenditure ought to be deployed in order to redress "cultural poverty" and to integrate the poor into the basic institutions of American life - "healthy families, communities, schools, workplaces and the other essential institutions", (page 231) - apparently unconcerned that the central project of the social sciences since the 1960 s has been to demonstrate just how bitterly contested are the very concepts he takes for granted such as "cultural poverty", "healthy" institutions and "the common good".

There is no doubt about Epstein's sincere conviction. But having pronounced a plague upon both the warring houses of poverty research, unfortunately he can offer a no more "rational" and no less "mythical" justification for his own "option for the poor" than those he has dismissed. The problem of poverty, as he wryly comments, remains polemical after all.

BERNICE MARTIN

Emeritus Reader in Sociology, University of London

\section{Getting Doctors to Listen}

Edited by Philip J Boyle, Washington, Georgetown University Press, 1998, 249 pages, US\$45/£34.95 (hc).

This book starts from the premise that there is massive variation in medical practice. Some of this variation must be inherent to the practice of medicine but some may represent unacceptable variation from good practice. With the ever-increasing amount of evidence being produced how can doctors be encouraged to use this information in their clinical practice? This book focuses on the problems facing both those producing and synthesising evidence. It is estimated that there are twenty kilograms of guidelines in every family practitioner's office. The book also addresses the use of guidelines by the practitioners.

The book is written mainly from the American perspective. It describes the formation of the Agency for Health Care Policy and Research (AHCPR). This organisation was responsible for some of the major guidelines produced in the United States. The book describes in detail the positive and negative aspects of some of these guidelines. It then deals in detail with this process of guideline production, using the example of otitis media with effusion.

This is where the book becomes more interesting, describing how the backgrounds of the individuals and their skills in epidemiology (or lack of skills) often introduced a potential for bias in these guidelines. The next stop after this was to address the role of research in answering clinical questions. If the process of developing guidelines threw up unanswered questions what type of research would answer this? More importantly would clinicians and the public believe it and then would they use it? Both these questions are followed by an interesting debate about the difference between the belief that a certain procedure will work and the development of evidence showing that the positive and negative effects of that procedure may not lead to clinical benefit. The authors then investigate the use of hormone replacement therapy and present some interesting facts about its potential effects. Why should so many people be encouraged to use medication when the effects are not clearly known? This is contrasted with other treatments of more immediate clinical benefit such as clot-busting agents in acute myocardial infarction and asks why there is a lack of use of this therapy. At what stage and why does clinical practice change? Not surprisingly there was no one short answer to this question. An example used to describe some of these issues was that of intensive (and lifethreatening) chemotherapy for metastatic breast carcinoma.

The last section, sadly, is not as conclusive as might be expected from reading the middle section. It describes the epidemiological issues involved in research and some questions to do with the validity of research. Finally the book starts to deal with the rather obvious problem of how a clinician deals with the evidence while taking into account the background and current health and social status of the patient. The author never suggests that this approach is novel. This is just as well. The Royal College of General Practitioners has spent the last 20 years advocating the approach of addressing the illness in the patient who is part of a society, rather than the purely disease-orientated approach.

It is necessary that the health beliefs of the patient be taken into account whilst at the same time appreciating his/her social and medical background. Helping the patient to understand the implications of the various choices is then part of the medical process. This is one of the major educational aims of the vocational training scheme for general practitioners in this country.

Throughout the book there is a hint of awareness of the underlying discussion about value judgements made by health professionals and the advancement of medical science.A case is put forward for separating the effects of medicine and its benefits, although the authors then acknowledge that the benefits of medicine are fundamentally not knowable by medical science. So at the end of the book I know more about the process of drawing up guidelines, more about the practice of medicine, but am still left with many unanswered questions. I was never quite clear that the book had focused enough on addressing specific issues. Although I was not expecting answers to the questions posed I did expect a bit more debate and clarity.

Unlikely to be one for my bookshelf. More likely to be looked at in the library.

MARTIN DAWES

Lecturer in Primary Care, University of Oxford

\section{The Issue of Abortion in America: An Exploration of Social} \section{Controversy}

\author{
R Cavalier, P Covey, E Style and \\ A Thompson, London, Routledge, \\ 1998, CD-ROM, £40.
}

For some the abortion question is simple - kill or let kill. So it must seem to the person who last year shot $\mathrm{Dr}$ Slepian, who worked in a United States abortion clinic and whose name has now been added to the roll-call of doctors and clinic workers who have been killed or maimed by the violent fanatics of the fundamentalist fringe.

The debate on abortion is often scarcely more sophisticated. Even to describe the slanderous cacophony which passes for dialogue, at least in the public eye, as a debate at all, is to distort the language to breaking point. The perspectives on abortion are chasms apart - there is almost no perceptible common ground. It's a battle of slogans: life versus murder; motherhood versus infanticide; family values 